\title{
Gareth Wall
}

Commonwealth Local Government Forum

United Kingdom

Email: gareth.wall@clgf.org.uk

wallgareth@gmail.com

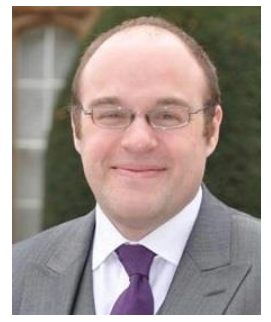

\section{Gordon Morris}

Centre for Rural Policy Research, University of Exeter, and Bournemouth University

United Kingdom

Email: g.r.morris@exeter.ac.uk

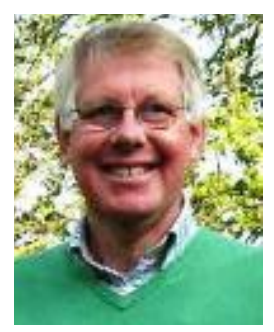
grmmorris@btinternet.com

\section{Editorial}

A couple of months before the adoption of the 2030 Agenda for Sustainable Development and the associated 17 goals at the UN General Assembly in September 2015, the international community came together in Ethiopia for the Third International Conference on Financing for Development and adopted the Addis Ababa Action Agenda. These commitments for financing the post-2015 development agenda are particularly important for local government around the world in that for the first time, the UN member states "acknowledge[d] that expenditures and investments in sustainable development are being devolved to the subnational level, which often lacks adequate technical and technological capacity, financing and support." The action agenda goes on to commit the nation states to "scaling up international cooperation to strengthen capacities of municipalities and other local authorities" and to "strive to support local governments in their efforts to mobilize revenues". This includes a particular acknowledgment of the need to "strengthen municipal bond markets to help subnational authorities to finance necessary investments" and of particular note to the Commonwealth member states is the commitment to "support cities and local authorities of developing countries, particularly in least developed countries and small island developing States, in implementing resilient and environmentally sound infrastructure" (Addis Ababa Action Agenda, paragraph 34, www.un.org/esa/ffd/wp-content/uploads/2015/08/AAAA_Outcome.pdf).

DOI: https://doi.org/10.5130/cjlg.v0i20.6503

Citation: Commonwealth Journal of Local Governance 2017, 20: 6503, https://doi.org/10.5130/cjlg.v0i20.6503

(c) 2019 Gareth Wall and Gordon Morris. This is an Open Access article distributed under the terms of the Creative Commons Attribution 4.0 Unported (CC BY 4.0) License (https://creativecommons.org/licenses/by/4.0/), allowing third parties to copy and redistribute the material in any medium or format and to remix, transform, and build upon the material for any purpose, even commercially, provided the original work is properly cited and states its license. 
In this issue's lead paper, Paul Smoke builds on these commitments to examine the requirements and options for local government finance and provides suggestions for strategic implementation. $\mathrm{He}$ concludes by linking fiscal decentralisation reforms to Agenda 2030, arguing that " $[d]$ eveloping dynamic processes that make use of improved information and include relevant stakeholders in a meaningful way can support strategic advances in meeting the SDGs with greater contributions from more empowered, capable and motivated [local government]." Judy McGregor and Karen Webster's paper that follows relates directly to SDG 5 on gender equity. Through their analyses of data on elected women's representation in Auckland from both before and after the city council's amalgamation they show how the promised improvements to substantive representation has yet to materialise. This is followed by Gordon Morris's paper on sustainable rural development. The paper explores both the extent to which organisations once central to policy development in England are remembered, and where now, in their absence, influence over policy lies.

Staying with sustainability, Anél du Plessis and Oliver Fuo address the inherent constitutional tensions relating to environmental matters in South Africa and argue for a primacy of local government and the need for cooperative environmental governance. Staying in the rainbow nation, Adam Andani finds that whilst South Africa's integrated development planning's participatory processes facilitate awareness of participation, it is ward councillors that are crucial to operationalising participation that is reflective of community diversity. Heading to Australia, Emily Killin and Alan March challenge the appropriateness of development funding mechanisms and argue that path dependency has resulted in mechanisms that are more relevant for greenfield development than infill development. Participatory planning and participatory budgeting processes in Bangladesh are examined by Shuva Chowdhury, before Norbert Musekiwa and David Mandiyanike bring us back to Agenda 2030 with a review of Botswana's development vision and what this means for the localisation of the SDGs. To complete the section Muhammad Mustofa Kamal, Anwara Begum and Chowdhury Abdullah Al-Hossienie examine the roles of the executive and council in the decisionmaking process in Sylhet City Corporation.

Our three policy and practice papers come from Africa and provide excellent examples of innovative practice and critical commentary, with Kenneth Okwaroh Ochieng exploring accountability for health service delivery in Kenya's newly devolved counties, and Tinashe Chigwata and Sylvester Marumahoko examining intergovernmental planning and budgeting in Zimbabwe under the 2013 Constitution. This is followed by a detailed guide to increased accountability through Uganda's local government scorecard initiative by Lillian Muyomba-Tamale and Kiran Cunningham. To complete the issue, there are two engaging book reviews from colleagues at the UK's Local Government Information Unit, with Andrew Walker reviewing David Sweeting's (ed) Directly Elected Mayors in Urban Governance: Impact and Practice and Jonathan Carr-West reviewing Local Government in England: Centralisation, Autonomy and Control by Colin Corpus, Mark Roberts, and Rachel Wall. 